\title{
Hypercalcaemic stupor as a presentation of lymphosarcoma
}

\author{
G. D. SCHOTT ${ }^{1}$
}

From the Department of Neurology, Royal Free Hospital, London

SYNOPSIS A case is reported of a 32 year old woman with a two year history suggestive of schizophrenia who presented in stupor. This proved to be due to hypercalcaemia with a concomitant high ${ }^{\circ}$ cerebrospinal fluid calcium concentration associated with previously unsuspected lymphosarcoma. $\overrightarrow{0}$ Necropsy revealed no significant intracranial abnormality, and mechanisms that may have been:involved in the production of the impaired consciousness are discussed.

It is well known that neurological disorders may accompany hypercalcaemia, but in most cases the aetiology of the disturbed calcium state has been evident for some time before. The patient described here presented in stupor without indication of the serious underlying cause; this proved to be due to hypercalcaemia associated with a highly malignant and previously asymptomatic lymphosarcoma.

\section{CASE REPORT}

P.L., a 32 year old West Indian woman, was admitted in stupor in August 1974. Two years previously she had developed intermittent shaking of the right side of her body, auditory and visual hallucinations, and features of paranoia and delusions. No abnormal signs were elicited and an electroencephalogram (EEG) was normal. A diagnosis of schizophrenia was made and she was treated with various phenothiazine preparations and hospitalized on five occasions for recurrence of these symptoms.

She was referred to this hospital having had a five day history of chest infection with cough and nonpurulent sputum production, but three days before admission she had begun to feel increasingly unwell with mild headache and generalized weakness. On the morning of admission she had been found collapsed on the floor, confused, drowsy, and unresponsive.

On admission she was afebrile, her skin felt unduly hot, and she was slightly dehydrated. Her 1 Address for correspondence: Dr G. D. Schott, Department of
Neurology, Royal Free Hospital, London NW3 2QG.

(Accepted 10 December 1974.) pulse was regular at 110 /minute, blood pressure $\dot{\omega}$ $140 / 70 \mathrm{mmHg}$. There was enlargement of the posterior cervical, axillary, and left inguinal lymph nodes, $\dot{\omega}$ and moderate, smooth hepatosplenomegaly. A soft $\stackrel{\infty}{\sim}$ systolic murmur was audible over the left sternal윽 edge and a few coarse râles were heard over the right lung base. Neurological examination revealed stuporose patient who could be roused with difficuleg but was unable to speak coherently. There was $\overrightarrow{0}$ neck stiffness. The cranial nerves were normal, to pupils $4 \mathrm{~mm}$ in diameter and responding normally to light. Oculocephalic reflexes were normal. Little spontaneous movement of the limbs was present, although there was slight response to painful stimuli. The tendon reflexes were normal and plantar responses flexor.

An EEG showed diffuse slow wave activity at a $\overrightarrow{\overrightarrow{0}}$ frequency of 1-2 $\mathrm{Hz}$ over both hemispheres. The 3 cerebrospinal fluid (CSF) was under normal pressure and contained: red blood cells $2000 / \mathrm{mm}^{3}$, white blood cells $12 / \mathrm{mm}^{3}(18 \%$ polymorphonuclear cells, $82 \%$ lymphocytes); Gram stain revealed no organ- 0 isms and subsequent cultures and virological studies proved negative. The supernatant fluid was clear. The CSF glucose was $85 \mathrm{mg} / \mathrm{dl}$ (simultaneous blood sugar $95 \mathrm{mg} / \mathrm{dl}$ ), total protein $16 \mathrm{mg} / \mathrm{dl}$, albumin $₹$ $7 \mathrm{mg} / \mathrm{dl}$, and IgG constituted $1 \%$ of the total protein;으 the Lange colloidal gold curve was normal and CSF Wassermann reaction negative. Haematologicalo investigations revealed: haemoglobin $15.0 \mathrm{~g} / \mathrm{dl}$, white cell count 40000 cells $/ \mathrm{mm}^{3}$, about $75 \%$ of which were lymphocytes, many being atypical cells $N$ with occasional smear cells present; erythrocyte స్ట sedimentation rate (Westergren) $25 \mathrm{~mm} / \mathrm{hr}$; reticulo- $\sigma$ cyte and platelet counts and tests of bleeding and clotting time were normal. Plasma electrolytes were 
normal but the blood urea was elevated at 168 $\mathrm{mg} / \mathrm{dl}$.

A search for other metabolic abnormalities revealed a very markedly elevated serum calcium level of 18.1 (normal $8.5-10.5$ ) $\mathrm{mg} / \mathrm{dl}$, with a serum phosphorus level of 4.0 (normal $2.5-4.5$ ) $\mathrm{mg} / \mathrm{dl}$ and alkaline phosphatase activity of 23 (normal 3-13) $\mathrm{KA}$ units/dl. The CSF calcium was 8.2 (normal 4.15.9) $\mathrm{mg} / \mathrm{dl}$, phosphorus 1.4 (normal 1.4-2.1) mg/dl, and chloride $130 \mathrm{mmol} / \mathrm{l}$. Serum uric acid was elevated at $13.6 \mathrm{mg} / \mathrm{dl}$. The urinary excretion of calcium ranged from 100 to $1500 \mathrm{mg} /$ day and phosphorus from 450 to $1020 \mathrm{mg} /$ day. The following were normal: plasma and urinary proteins, albumin and IgG, IgA and IgM levels, serum creatinine, radiological examination of chest and skull, skeletal survey and intravenous urogram, and brain scan; bacteriological cultures of blood, urine, faeces, and sputum were negative. An electrocardiogram demonstrated sinus tachycardia with a $\mathrm{QT}_{\mathrm{c}}$ interval of 0.28 seconds, within the normal range. Estimation of parathyroid hormone showed no detectable activity.

A liver scan demonstrated hepatic enlargement with homogeneous dye uptake. Sternal bone marrow biopsy showed infiltration by primitive cells belonging to the lymphocytic series, and these cells together with some mature lymphocytes formed about $15 \%$ of all the nucleated cells. An inguinal node biopsy showed appearances of a poorly differentiated, highly malignant lymphosarcoma.

Management was directed towards reduction of the hypercalcaemia (Paterson, 1974). A saline diuresis was instituted and she received steroids, mithramycin, calcitonin, and disodium hydrogen phosphate. Allopurinol and chlorambucil were introduced for treatment of the lymphosarcoma. Her serum calcium levels fell slowly and became normal after nine days; serum phosphorus levels remained normal but the alkaline phosphatase activity was persistently elevated around $20 \mathrm{KA}$ units/dl. The blood urea and uric acid concentrations fell rapidly to normal. The white blood cell count remained between 20000 and 40000 cells $/ \mathrm{mm}^{3}$, although the abnormal appearances of the cells-which initially became more marked-gradually improved and the frank lymphoblastic changes and smear cells became less evident. A repeat EEG four days after admission when her hypercalcaemia had improved and her serum calcium level was $14.7 \mathrm{mg} / \mathrm{dl}$ showed no significant change, as did a third recording 10 days after her admission; the appearances did not correlate with her gradually improving clinical state. She failed to improve significantly for the first week but thereafter gradually became alert, was able to sit out of bed and eat a normal although calcium-free diet. She gave a rational and coherent account of past events, was fully orientated, and without obvious features suggestive of previous psychiatric illness.

Two weeks after admission, she developed a fulminating septicaemia, became incontinent, confused, and restless, and her serum calcium level rose from a normal value $(9.0 \mathrm{mg} / \mathrm{dl})$ to $15 \mathrm{mg} / \mathrm{dl}$ within 24 hours. Blood cultures revealed the presence of Staphylococcus Aureus and anaerobic streptococci and intravenous antibiotic therapy was instituted, but she suffered a cardiac arrest from which resuscitation was unsuccessful.

Necropsy demonstrated extensive lymphosarcomatous infiltration of enlarged lymph nodes, liver, spleen, upper lobe of the right lung, and left renal parenchyma. Both lungs were congested and purulent material was present in the major bronchi. The cardiovascular and endocrine systems, in particular the parathyroids, were normal, as were the bones. The nervous system was intact with normal meninges and macroscopic brain appearances and the cerebral arteries were patent. The brain was examined in detail at the Department of Neuropathology, Institute of Neurology, Queen Square, and no significant abnormalities were found; in particular there was no evidence of malignant infiltration in either the brain or leptomeninges.

\section{DISCUSSION}

The present report describes an unusual, neurological presentation of lymphosarcoma characterized by hypercalcaemic stupor. In disease as widespread as that encountered in this patient, although it is possible that other factors contributed to the overall clinical features, it would seem highly likely that severe hypercalcaemia was the critical one. Thus the clinical improvement after the return towards normal of the high serum calcium level and the impaired clinical state associated with its subsequent rapid increase make the association very probable. The contribution from the elevated blood urea is unlikely to have been significant since its early correction after rehydration was not associated with change in the patient's conscious level. Direct involvement of the central nervous system with malignant disease is also most unlikely to have been present in view of the CSF findings, and such involvement was excluded on examination of the brain at necropsy.

There is thus little doubt that this patient's stupor was caused by severe hypercalcaemia, and an elevated serum calcium concentration is a 
well-recognized cause of neurological disease including impaired consciousness (Henson, 1966; Plum and Posner, 1972). The association of disturbances of calcium concentration with psychiatric disorders is also well recognized (Plimpton and Gellhorn, 1956; Lehrer and Levitt, 1960), and it is possible that this patient's earlier history suggesting schizophrenia may have been due to hypercalcaemia, although at that time the EEG was normal. The EEG in the present case was consistent with a metabolic encephalopathy, and a variety of abnormal EEG changes has been recorded in hypercalcaemia, some associated with impaired consciousness (Moure, 1967; Allen et al., 1970). Interestingly, a period of some weeks' normocalcaemia is probably required before the EEG returns to normal (Allen et al., 1970), which is consistent with the observations in the present case where there was striking lack of correlation between the EEG appearances and the clinical state.

Although hypercalcaemia often accompanies malignant disease, it has only rarely been reported in lymphosarcoma. For instance, in a study of over 1200 cases of lymphosarcoma, Rosenberg et al. (1961) mention only four cases in which hypercalcaemia was present, and in two cases this was associated with bone involvement with malignant disease. In this large series stupor was not recorded as a presenting feature. Neurological manifestations including focal symptoms, convulsions, raised intracranial pressure, cranial and peripheral nerve palsies, and herpes zoster have frequently been noted in diseases of the lymphoreticular system, and an extensive literature has accumulated on this subject (for example, Hutchinson et al., 1958; Williams et al., 1959; Rosenberg et al., 1961; Currie et al., 1970; Currie and Henson, 1971). However, at least in lymphosarcoma, hypercalcaemia is often overshadowed by other features which have nearly always previously declared themselves. It is of interest that in patients with lymphomas having cerebral manifestations, a relatively high frequency of normal brain findings at necropsy and spontaneous regression of cerebral symptomatology were noted in an earlier review (Williams et al., 1959): the origin of these cerebral symptoms was unclear, and, since a specific search for hypercalcaemia was not undertaken, it is possible that this dis- order may have contributed to the cerebra年 features encountered.

The mechanisms involved in hypercalcaemico cerebral disturbances are not known, although calcium ions have critical effects on excitable membranes including those of cells of the centra.్. nervous system (Tschirgi, 1960; Winterstein 1961); noteworthy is the stupor that may be pro $\Rightarrow$ duced in animals by intraventricular applications of calcium salts (Winterstein, 1961). There is ac good correlation between the concentration of the ionized calcium fractions in CSF and plasma (Paupe, 1957), although the concentration of calcium ions in the former is lower, dues in part to the difference in protein content between these two fluids (Davson, 1967). The initially very high serum calcium level in theo present case was reflected by the high CSF level, $\overline{5}$ and it is reasonable to assume that the cells within the central nervous system were simi-e larly exposed to a markedly elevated calciumi concentration.

The origin of hypercalcaemia arising in associa-을 tion with malignant disease including lymphesarcoma is also often not clear. In some instanceso bone destruction plays a part (Moses a $\mathrm{a}$ 前. Spencer, 1963), but in others (Myers, 19ز; Plimpton and Gellhorn, 1956), as in the presentur case, there is no evidence of bone involvement? and other factors must be considered. Exceptionally, an associated parathyroid tumour has been⿳亠二口 found, but in the patient described above noto only were the parathyroid glands normal ate necropsy but plasma parathyroid hormone was $\overrightarrow{\overrightarrow{0}}$ undetectable, presumably as a result of suppression of hormone secretion by the hypercalcaemia Parathyroid-hormone-like polypeptides (perhaps immunologically distinct from 'normal' parathyroid hormone), non-parathyroid humora? substances, an osteolytic sterol, and parathyro-3. tropic substances have all been implicated asi causative agents in the hypercalcaemia associated with malignancy (Wills, 1974) but the role ofo such substances remains uncertain.

The present case supports the view of Plumo and Posner (1972) that it is 'sometimes reward ing to obtain a serum calcium determination in patients with unexplained delirium'. Unfortunately, the patient's demise occurred shortly afterw her admission, and it is salutary to recall thate this may have been due to sudden hyper은 
calcaemia affecting the heart, despite continuation of therapy for this condition.

I am indebted to Dr J. Newsom Davis and Professor P. K. Thomas for permission to publish a report of this case under their care, and for valuable discussion. I am also grateful to Professor M. R. Wills for advice on some of the metabolic aspects, to Dr G. Francis and Professor A. V. Hoff brand on haematological management, and to Dr B. MacGregor and Professor W. Blackwood, Department of Neuropathology, Institute of Neurology, Queen Square, for the necropsy findings on the brain.

\section{REFERENCES}

Allen, E. M., Singer, F. R., and Melamed, D. (1970). Electroencephalographic abnormalities in hypercalcemia. Neurology (Minneap.), 20, 15-22.

Currie, S., and Henson, R. A. (1971). Neurological syndromes in the reticuloses. Brain, 94, 307-320.

Currie, S., Henson, R. A., Morgan, H. G., and Poole, A. J. (1970). The incidence of the non-metastatic neurological syndromes of obscure origin in the reticuloses. Brain, 93, 629-640.

Davson, H. (1967). The Physiology of the Cerebrospinal Fluid, p. 143. Churchill: London.

Henson, R. A. (1966). The neurological aspects of hypercalcaemia: with special reference to primary hyperparathyroidism. Journal of the Royal College of Physicians of London, 1, 41-50.

Hutchinson, E. C., Leonard, B. J., Maudsley, C., and Yates, P. O. (1958). Neurological complications of the reticuloses. Brain, 81, 75-92.

Lehrer, G. M., and Levitt, M. F. (1960). Neuropsychiatric presentation of hypercalcemia. Journal of the Mount Sinai Hospital, New York, 27, 10-18.
Moses, A. M., and Spencer, H. (1963). Hypercalcemia in patients with malignant lymphoma. Annals of Internal Medicine, 59, 531-536.

Moure, J. M. B. (1967). The electroencephalogram in hypercalcemia. Archives of Neurology (Chic.), 17, 34-51.

Myers, W. P. L. (1956). Symposium on medical aspects of cancer. Clinical aspects and management of hypercalcemia. Medical Clinics of North America, 40, 871-885.

Paterson, C. R. (1974). Drugs for the treatment of hypercalcaemia. Postgraduate Medical Journal, 50, 158-162.

Paupe, J. (1957). Comparaison entre fractions calciques de liquides céphalo-rachidiens et de sérums normaux chez l'homme. Comptes Rendus des Séances de la Société de Biologie, 151, 318-320.

Plimpton, C. H., and Gellhorn, A. (1956). Hypercalcemia in malignant disease without evidence of bone destruction. American Journal of Medicine, 21, 750-759.

Plum, F., and Posner, J. B. (1972). The Diagnosis of Stupor and Coma, 2nd edn, p. 202, Davis: Philadelphia.

Rosenberg, S. A., Diamond, H. D., Jaslowitz, B., and Craver, L. F. (1961). Lymphosarcoma: a review of 1269 cases. Medicine (Balt.), 40, 31-84.

Tschirgi, R. D. (1960). Chemical environment of the central nervous system. In Handbook of Physiology. Section 1. Neurophysiology. Vol. 3, pp. 1865-1890. Edited by J. Field, H. W. Magoun, and V. E. Hall. American Physiological Society: Washington.

Williams, H. M., Diamond, H. D., Craver, L. F., and Parsons, H. (1959). Neurological Complications of Lymphomas and Leukemias. Thomas: Springfield, Ill.

Wills, M. R. (1974). Hypercalcaemia. British Journal of Hospital Medicine, 11, 279-288.

Winterstein, H. (1961). The actions of substances introduced into the cerebrospinal fluid and the problem of intracranial chemoreceptors. Pharmacological Reviews, 13, 71107. 